\title{
Physical modeling of intermediate cross-shore beach morphology: Transients and equilibrium states
}

\author{
F. Grasso, ${ }^{1}$ H. Michallet, ${ }^{1}$ E. Barthélemy, ${ }^{1}$ and R. Certain ${ }^{2}$ \\ Received 30 January 2009; revised 18 May 2009; accepted 29 May 2009; published 1 September 2009.
}

[1] Laboratory experiments on cross-shore beach morphodynamics are presented. A lightweight sediment (density $\rho_{s}=1.19 \mathrm{~g} \mathrm{~cm}^{-3}$ ) model is used in order to fulfill a Shields number and Rouse number scaling. This choice aims at correctly reproducing bed load transport as well as suspension dynamics. Terraces and barred beach profiles obtained in the experiments also present close similarities with profiles observed in the field. In order to question the concept of equilibrium beach profile, wave forcings conforming to a JONSWAP spectrum were imposed over long periods (up to more than a hundred hours). An average bottom evolution velocity is defined and used to determine when the profile reaches equilibrium. Usually, beach profiles are characterized according to the Wright and Short (1984) classification based on the Dean number $\Omega$. This well-known classification is investigated and refined in the intermediate range, that is, for $1 \leq \Omega<5$. For $\Omega$ close to 1, a typical reflective profile is obtained. Terraces are obtained for the $\Omega=2.5$ cases. For $\Omega \approx 3.7$, the profiles exhibit two parts: a mild dissipative offshore slope producing low reflection and a steeper beach face with slightly higher reflection. The wave dissipation, velocity skewness, and acceleration skewness are computed from the free surface elevation time series. The dissipation and wave nonlinearities patterns are similar for similar equilibrium beach profiles, that is, with the same Dean number. Dissipation peaks coincide with bottom slope transitions as higher energy dissipation occurs with milder bottom slope sections. Besides, the uniformity of volumetric wave energy dissipation seems to concern only a limited zone of beaches with a widely developed surf zone.

Citation: Grasso, F., H. Michallet, E. Barthélemy, and R. Certain (2009), Physical modeling of intermediate cross-shore beach morphology: Transients and equilibrium states, J. Geophys. Res., 114, C09001, doi:10.1029/2009JC005308.

\section{Introduction}

[2] The morphology of a beach is mainly controlled by wave climate, tide and sediment characteristics. Cross-shore morphology of sandy beaches is an important issue for coastal erosion. Even though cross-shore sediment fluxes are usually a few orders of magnitude smaller than longshore transport, the cross-shore beach profile has a strong influence on longshore velocity profiles and therefore on longshore sediment fluxes. The beach profile is the result of the trade off between onshore and offshore fluxes. The direction of the cross-shore fluxes is a key point for predictive tools and is closely related to the nonlinear characteristics of the incoming waves such as asymmetry and velocity skewness [Bailard, 1981; da Silva et al., 2006]. This complexity is very difficult to reproduce with numerical models and a physical model then becomes an interesting alternative.

\footnotetext{
${ }^{1}$ Laboratoire des Ecoulements Géophysiques et Industriels, Grenoble, France.

${ }^{2}$ IMAGE EA4218, Université de Perpignan, Perpignan, France.
}

Copyright 2009 by the American Geophysical Union. 0148-0227/09/2009JC005308
[3] Because of this complexity, the concept of equilibrium beach profile is very useful. Indeed long-term beach changes can be estimated by measuring the "distance" between the current beach profile and the equilibrium profile it should assume for a given wave climate. Using such a framework, some standard engineering tools (SBEACH for example) for cross-shore profile changes consider equilibrium profiles [Dean, 1991; Miller and Dean, 2004] as target profiles. These are essentially empirically determined but were initially justified by a physical argument of uniform volumetric wave dissipation in the surf zone [Dean, 1977; Wang and Kraus, 2005]. These profiles have the following expression:

$$
h=\alpha\left(x_{s}-x\right)^{2 / 3},
$$

where $h$ is the water depth at the cross-shore position $x$ ( $x$ oriented onshore) and $x_{s}$ is the shoreline position. Dean [1977] and Moore [1982] show that the constant of proportionality $\alpha$ can be related to the size of the beach sediment or, alternately, the fall velocity. Other assumptions and more detailed sediment transport physics are used by Plant et al. [2001] who also obtain equilibrium profiles. On equilibrium beach profiles the mean cross-shore sediment 
fluxes are zero. Stemming from this constraint, Bowen [1980] and Dronkers [2005, pp. 387-414], using simple sediment flux evaluations, show that these profiles are also compatible with the equilibrium between a destructive force such as gravity and a constructive force such as onshore bed load sediment transport by waves. The equilibrium beach profile formulation (1) can be obtained through a number of independent arguments that seem reasonable on physical grounds. The assumption that the equilibrium beach profile in the surf zone corresponds with uniform wave energy dissipation per unit volume, suggested by Dean [1977], has been recently analyzed by Wang and Kraus [2005] for regular and irregular waves generated during runs less than $10 \mathrm{~h}$ in the SUPERTANK flume. The authors concluded that under irregular waves, the pattern of wave energy dissipation across a large portion of the surf zone became relatively uniform while the profile evolved toward equilibrium. One of our aims is to question the concept of equilibrium beach profile in the framework of physical modeling. Do such profiles exist since some of the very few examples of flume experiments have focused on transients such as erosion or nearshore bar growth [Dette and Uliczka, 1987; Dally, 1987; Dette et al., 2002]?

[4] Clearly, because of the ever-changing wave climate in natural environments, equilibrium profiles can only be retrieved as spatial long-shore averages or mean interannual profiles. In detail it has been claimed that different equilibrium profiles correspond to each season in conjunction with well-defined wave climates [Larson and Kraus, 1994] leading, for instance, to the so-called summer profiles and winter profiles. Flume experiments can overcome the drawback of defining an equilibrium beach profile as a temporal mean. As long as one is patient enough to run lengthy experiments for given wave conditions, equilibrium profiles can be obtained [Kamalinezhad, 2004; Kamalinezhad et al., 2004; Wang and Kraus, 2005; Grasso et al., 2007; Michallet et al., 2007].

[5] Beach profiles are generally more complex than the simple Dean concave-up equilibrium profile. Some tend to have a convex part near the shoreline and a concave part further offshore. Amongst these double convex profiles the terrace-like or step-like profiles are observed in macrotidal wave dominated environments [Wright and Short, 1984; Black et al., 2002]. It has been shown that some equilibrium beach profiles are a combination of an upper profile and a lower profile [Inman et al., 1993; Bernabeu et al., 2003]. In this two-section modeling approach a discontinuity point therefore separates the beach into two sections: the shoaling section and the surf section. The discontinuity point at depth $h_{r}$ coincides with the break point. For irregular waves the breaking index $\gamma$ is defined at the break point of depth $h_{r}$ by

$$
h_{r}=\frac{1}{\gamma} H_{r m s}
$$

with $\gamma$ between 0.4 and 0.6 at the break point [Wang and Kraus, 2005], $H_{r m s}$ being the root mean square wave height. The depth $h_{r}$ at the break point is expressed in terms of the significant wave height $H_{s}$ to yield

$$
h_{r}=\beta H_{S} \text { with } 1.1 \leq \beta \leq 1.7 \text {. }
$$

Longshore bars are also frequently observed on beach profiles. Some studies argue that they are perturbations of equilibrium profiles [Ribas Prats, 2003]. Observed barred profiles are constantly evolving including cyclic behavior [Ruessink and Kroon, 1994] on timescales as long as decades. Knowledge of the seasonal variability of nearshore bars [Holman and Sallenger, 1993] has increased considerably in recent years due to the use of video remote sensing techniques [Lippmann and Holman, 1990; Van Enckevort and Ruessink, 2001]. Analysis by Lippmann and Holman [1990] shows that beach states with bars are indeed frequently observed but that they undergo frequent transitions. Analysis of Duck profiles [Larson and Kraus, 1994] shows that summer profiles are the result of an accretion process in which sand of the winter profile is transported onshore. Bar migration has been identified as one of the mechanisms of such accretion [Gallagher et al., 1998]. This beach recovery is also known to be associated with mild wave climates. Bar formation has been investigated in flume experiments but essentially as an erosion process [Roelvink and Stive, 1989; Guannel et al., 2007; Hoyng, 2008] in which undertow currents move sediment offshore [Thornton et al., 1996; Gallagher et al., 1998].

[6] Guannel et al. [2007] investigated onshore bar migration in a specifically designed run during the CROSSTEX experiments. Onshore bar migrations are probably due to a combination of subtle mechanisms [Elgar et al., 2001; Hoefel and Elgar, 2003; Henderson et al., 2004; Hsu et al., 2006; Foster et al., 2006]. This questions the relevancy of laboratory experiments to address such questions. It is well known that downscaled experiments with sand have difficulty in reproducing suspensions that behave dynamically as in nature. This is why a few experiments at scale 1 with sand have been recently reported in the literature [Guannel et al., 2007]. Wang and Kraus [2005] also present results from the large-scale SUPERTANK laboratory experiment. With regard to the dimensions of the flume $(104 \mathrm{~m}$ long, $3.7 \mathrm{~m}$ wide), these experiments may be considered as full scale for moderate waves $\left(H_{s} \leq 0.8 \mathrm{~m}\right)$. The maximum duration of irregular wave runs (JONSWAP spectrum with a peak enhancement factor of 3.3) is $3 \mathrm{~h} 29 \mathrm{mn}$ in the SUPERTANK experiments. It can be observed that most profile variations are restricted to shallow water such that $h<2 H_{s}$. In contrast to the SUPERTANK experiment, our present experiments aim at reproducing profile changes in water as deep as $4 H_{s}$ and for long periods up to $115 \mathrm{~h}$. Recently, Henriquez et al. [2008] also addressed scaling laws and concluded on the relevant use of coarse, lightweight particles for studying nearshore sediment transport in a physical model. The innovative aspect of the experiments presented in this paper is primarily the simulation of a wide range of irregular wave climates in a small-scale lightweight sediment model able to satisfy the laws of similitude over long periods.

[7] The flume experiments and similitude conditions are described in section 2. In section 2 some beach profiles at Duck and Lido beach (Sète, France) and the associated dimensionless numbers are compared to those of our experiments. Section 3 is devoted to the morphodynamics and presents a detailed description of the beach profile changes. Equilibrium states are characterized and classified in terms of the Dean number. The hydrodynamics related to the 


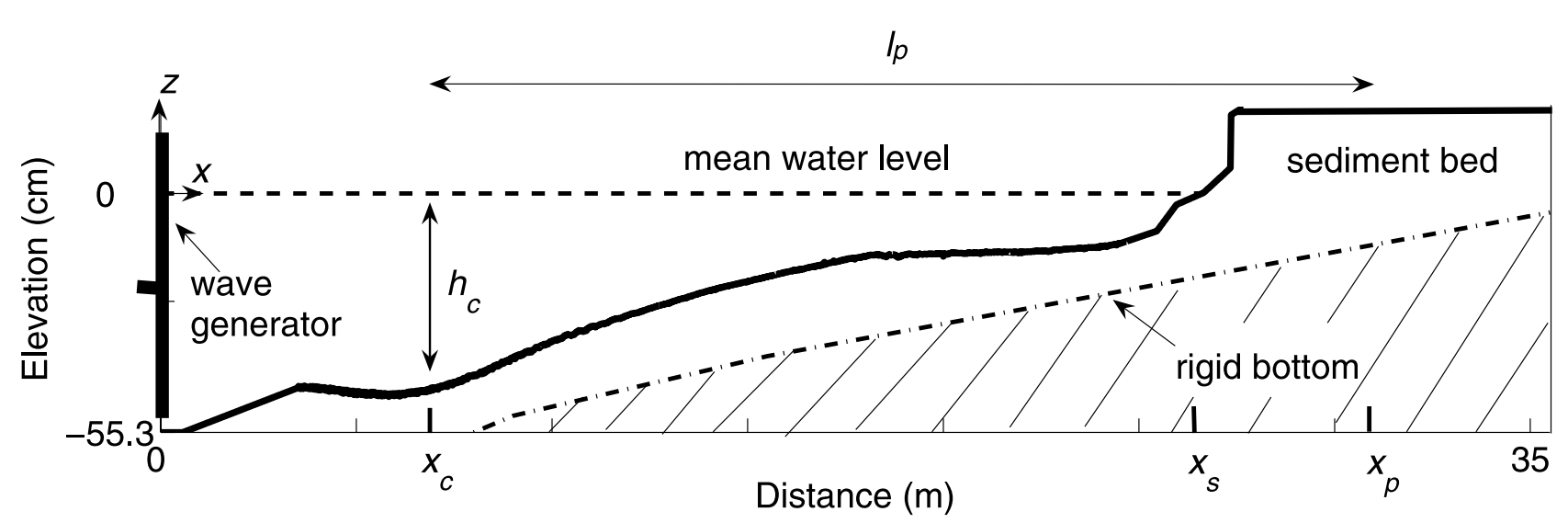

Figure 1. Schematic diagram of the LEGI wave flume: $l_{p}$ is the profile length from the cross-shore position $x_{c}$ of the closure depth $h_{c}$ to the cross-shore position $x_{p}$ of the most offshore point on the dune that does not change during an experiment; $x_{s}$ is the shoreline position.

equilibrium profiles are then described in section 4. Conclusions are given in section 5 .

\section{Description of Flume Experiments and Similitude Conditions}

\subsection{Experimental Setup}

[8] Our experiments were carried out in a flume $36 \mathrm{~m}$ long and $55 \mathrm{~cm}$ wide equipped with a piston wave generator (Figure 1). The still water depth at the wave maker is $h_{0}=$ $55.3 \mathrm{~cm}$. The sloping bottom consists of a loose material of low density $\left(\rho_{s}=1.19 \mathrm{~g} \mathrm{~cm}^{-3}\right)$ with a median diameter $d_{50}=$ $0.6 \mathrm{~mm}$ (corresponding settling velocity $w_{s}=2.1 \mathrm{~cm} \mathrm{~s}^{-1}$ ). It covers a rigid sloping bottom in some cases. The sediment layer over the rigid bottom is at least $5 \mathrm{~cm}$ thick in all the beach profiles presented in this paper. The mean overall beach slope is roughly $1 / 45$.

[9] Using a partially deterministic irregular wave synthesis [Hughes, 1995, p. 397], irregular waves are generated according to a JONSWAP spectrum with a peak enhancement factor of 3.3 [Goda, 1985, p. 26]. A linear combination of 10000 random sinusoidal components is used to define $30 \mathrm{mn}$ wave sequences. There is neither wave absorption nor second-order correction on the wave maker motion. A given $30 \mathrm{mn}$ wave sequence can be repeated continuously as much as desired.

[10] Twelve wave gages (acquisition at $50 \mathrm{~Hz}$ ) are mounted on trolleys and measure instantaneous water elevations. The root mean square wave height $H_{\text {rms }}$ is computed with the zero down-crossing technique for positions all along the beach profile.

[11] It is checked that the wavefield conforms to the expected spectrum and follows a Rayleigh distribution at $2 \mathrm{~m}$ downstream of the wave maker, as shown, for instance, in Figure 2. Limited energy is seen in the infragravity domain of the spectrum. This corresponds to seiching modes generated by wave breaking [Michallet et al., 2007; Grasso et al., 2007]. The contribution of these long waves to the sediment transport is expected to be weak to negligible compared to wave nonlinearities and undertow effects [Ruessink et al., 2007]. Their peak frequency and structure (node and antinode positions) mainly depend on the beach length and mean slope and are therefore similar for all the experiments presented in this paper. The variety of beach response described in the following would indicate that infragravity waves play a minor role on beach morphodynamics. The good agreement of the measured wave height distribution with the target Rayleigh distribution (Figure 2b) also suggests that a reflected waves absorption device is not needed for producing the desired irregular wave climates. Each wave sequence corresponds to a wave
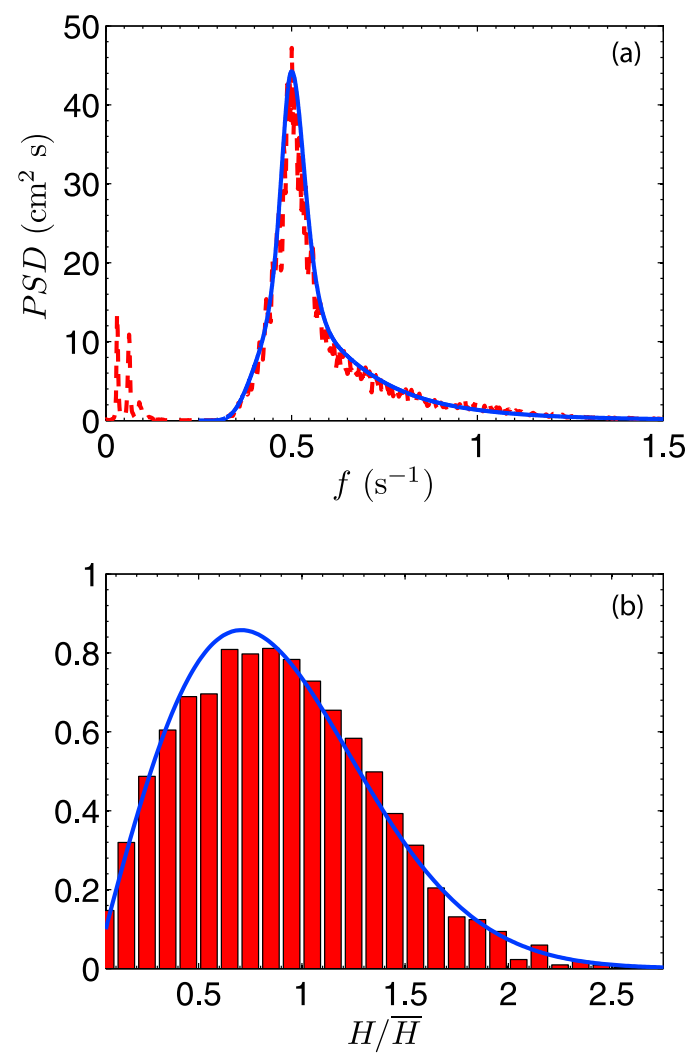

Figure 2. Experimental results and theoretical targets (solid lines) at $2 \mathrm{~m}$ downstream of the wave maker for the wave climate B1: (a) frequency distribution of power spectral density compared to the JONSWAP spectrum and (b) wave height distribution compared to the Rayleigh distribution with mean wave height $\bar{H}=6.4 \mathrm{~cm}$. 
Table 1. Wave Conditions Used in This Study, Related Dimensionless Numbers From Equations (4)-(10) Computed at the Closure Depth $h=4 H_{s}$, Durations of the Experiments, and Distance From Initial to Equilibrium Bottom Profiles

\begin{tabular}{|c|c|c|c|c|c|c|c|c|c|c|}
\hline Wave Climate & $H_{S}(\mathrm{~cm})$ & $T_{p}(\mathrm{~s})$ & $\Omega$ & $\operatorname{Re}\left(\times 10^{5}\right)$ & $F r$ & $\Theta$ & Rou & Duration $(\mathrm{h})$ & $T_{e q}(\mathrm{~h})$ & Distance $\Delta(\mathrm{mm})$ \\
\hline A & 3 & 2 & 0.7 & 0.1 & 0.04 & 0.18 & 3.7 & 9.4 & 3.1 & 20.8 \\
\hline B1 & 10.7 & 2 & 2.5 & 0.7 & 0.08 & 0.38 & 2.6 & 41.3 & 22.7 & 30.3 \\
\hline B2 & 10.7 & 2 & 2.5 & 0.7 & 0.08 & 0.38 & 2.6 & 57.8 & 32.9 & 64.4 \\
\hline $\mathrm{C}$ & 16 & 3 & 2.5 & 1.3 & 0.07 & 0.46 & 2.3 & 115.1 & 42 & 149.3 \\
\hline D & 10.7 & 1.4 & 3.6 & 0.6 & 0.12 & 0.35 & 2.7 & 6.7 & 3.8 & 12 \\
\hline $\mathrm{E}$ & 12.5 & 1.6 & 3.7 & 0.7 & 0.11 & 0.39 & 2.5 & 33.9 & 32.3 & 98.7 \\
\hline $\mathrm{F}$ & 16 & 2 & 3.7 & 1.1 & 0.10 & 0.45 & 2.3 & 30.5 & 30.5 & 71.3 \\
\hline
\end{tabular}

climate characterized by the significant wave height at the wave maker $H_{s}$ and the spectrum peak period $T_{p}$. A summary of the wave climates prescribed during the experiments is given in Table 1.

[12] Bottom profiles are recorded between wave series using an acoustic profiler mounted on a motorized trolley. Starting from a given bottom profile, wave sequences are repeated until an equilibrium state is reached. The equilibrium state is characterized in section 4 . The initial bottom profile of an experiment is a profile produced by previous wave sequences. The initial profile corresponds to an equilibrium state only for experiment $\mathrm{C}$, produced previously by experiment $\mathrm{F}$. The duration of each experiment, the time to reach equilibrium state and the distance from initial to equilibrium profiles are also indicated in Table 1 . These are discussed further in section 3.1. Although it should depend on the bed slope [Unal and Bayazit, 1998], the closure depth in all our set of experiments was found to be roughly $4 H_{s}$. This is probably due to the fact that in all our runs the mean beach slopes are similar. Attempts to compare our findings with empirical relations based on extreme wave heights obtained in natural environments [Hallermeier, 1978; Komar, 1998] were inconclusive.

[13] Values of dimensionless numbers are also indicated in Table 1. The choice of the sediment and wave conditions was determined through similitude considerations, as detailed in section 2.2.

\subsection{Dimensionless Numbers}

[14] Our laboratory experiments are designed to reproduce natural beach profiles and changes. The physics and hydraulics of movable bed models depend on (1) the wave parameters, $H_{s}$ the significant wave height and $T_{p}$ the peak wave period; (2) the sediment parameters, $d$ the sediment diameter and $\rho_{s}$ the density of the sediment; and (3) the water depth $h$, the fluid density $\rho$, the fluid kinematic viscosity $\nu$ and the gravity $g$.

[15] Hence these models are characterized by 8 independent parameters [Kamphuis, 1985]. This implies that the ideal downscaling would require scaling 5 dimensionless numbers, which is known to be very difficult. In the following we discuss which scaling is favored. The Froude scaling is the primary requirement for physical models involving waves [Dean and Dalrymple, 2001]. The Froude number is written

$$
F=\frac{H_{s} \omega_{p}}{2 \sqrt{g h}}
$$

where $H_{s}$ is the significant wave height, $\omega_{p}=2 \pi / T_{p}$ is the angular frequency and $h$ is the water depth. We also choose an undistorted model since wave dynamics, shoaling, breaking and turbulence generation by the waves are phenomena to be modelled correctly. As a consequence a single length scale $\lambda_{l}$ will be chosen $\left(\lambda_{i}\right.$ is the ratio of the model value to the prototype value of parameter $i$ ). The Froude similitude between nature and the model implies that the timescale is

$$
\lambda_{t}=\sqrt{\lambda_{l}}
$$

The wave Reynolds number is usually not scaled even in movable bed models, and will not be here. Nonetheless, this number reads

$$
\operatorname{Re}=\frac{A \omega_{p} h}{\nu},
$$

where $\nu$ is the fluid viscosity and $A$ is the particle excursion at the bottom:

$$
A=\frac{H_{\mathrm{rms}}}{2 \sinh k h},
$$

$k$ being the wave number. The sediment transport similitude is achieved in both shoaling and surf zones by adopting Shields and Rouse scalings. On the one hand the Shields number is defined by

$$
\Theta=\frac{1}{2} f_{w} \frac{\left(A \omega_{p}\right)^{2}}{g\left(\rho_{s} / \rho-1\right) d_{50}},
$$

where $f_{w}$ is a wave friction factor which, according to Swart [1974], can be approximated as

$$
f_{w}=\exp \left[5.213\left(\frac{2.5 \times d_{50}}{A}\right)^{0.194}-5.977\right]
$$

In the present context, the Shields number measures whether the sediment is set in motion by the waves and what the transport regime is (bed load, suspension, sheet flow, etc). It also indicates if ripples can form [Nielsen, 1992]. On the other hand, the Rouse number reads

$$
R o u=\frac{w_{s}}{u^{\prime}},
$$

where $u^{\prime}$ is the turbulent intensity of the flow field, which is approximated by

$$
u^{\prime}=\kappa \sqrt{f_{w} / 2} A \omega_{p},
$$


with $\kappa$ the von Karman constant (0.4) [Soulsby, 1997]. This number is relevant for characterizing sediment particle motions in a turbulent flow as in the breaking and outer surf zones, where sediment suspension is triggered and fueled by different turbulence sources (boundary layers, breaking). Considering a characteristic length (the water depth, for instance), it can be thought of as the ratio of a turbulent timescale to a settling timescale.

[16] Choosing a length scale and prescribing Froude scaling in an undistorted model imposes all the hydrodynamic scaling. The remaining parameters to be chosen are thus the sediment density and diameter, both of which will be determined with the Shields and Rouse scalings. These requirements led to the choice of a coarse lightweight sediment, as described in section 2.1. Consequently the immersed weight of the sediment $\left(\rho_{s} / \rho-1\right)$ is not scaled since water is the fluid in both the experiments and nature.

[17] The scaling choice will be more thoroughly justified in section 2.3 in comparison with natural beaches. Our approach is somewhat different from that of Dean and Dalrymple [2001, p. 310], who argued that morphological models with sand can be based on Froude and Dean scaling only. Other dimensionless numbers can be derived from those just described and are useful for the following.

[18] The particle Reynolds number is one of them. It is written

$$
R e_{p}=\frac{A \omega_{p} d_{50}}{\nu}=\operatorname{Re} \frac{d_{50}}{h}
$$

This Reynolds number quantifies the inertia of the flow around the sedimentary particle compared to the viscous drag. It indicates whether the flow around the particle is laminar or turbulent. The particle Reynolds number is linked to the wave Reynolds number by a factor $d_{50} / h$, which is a sort of Keulegan-Carpenter number. The parameter $R e_{p}$ is one used in the Shields diagram to decide whether the sediment is set in motion or not.

[19] The Dean number [Dean, 1973] is often used for discussing morphological beach states. It reads

$$
\Omega=\frac{H_{s}}{T_{p} w_{s}} .
$$

This number is commonly interpreted as being the ratio of a particle settling time $\left(H_{s} / w_{s}\right)$ to the wave period and therefore indicates whether phase lag effects occur in sediment transport processes [da Silva et al., 2006]. This interpretation shows that it is merely a rewriting of the Rouse number and not an independent dimensionless number. Since the work by Wright and Short [1984], this number has been known to be relevant for the modal classification of cross-shore beach profiles. Dissipative beaches characterized by a mild slope and spilling breakers are expected for $\Omega \geq 5$ while reflective beaches with a steep slope and surging breakers correspond to $\Omega \leq 1$ [Wright and Short, 1984; Masselink and Short, 1993; Bernabeu et al., 2003]. In the intermediate range defined by $1 \leq \Omega \leq 5$ beaches tend to have a moderate mean slope, breaking can be either plunging or spilling, and longshore bar-trough systems, rhythmic bars and terraces can be observed.
[20] Wright and Short [1984] also used an equivalent of the surf parameter $\xi$ [Battjes, 1974], which is defined as

$$
\xi=\frac{m}{\sqrt{H_{s} / L_{\infty}}},
$$

with $m$ the local beach slope and $L_{\infty}$ the deep water wavelength.

[21] The choice of the scaling just described is now assessed by comparison with natural beach morphologies which relate to the intermediate range $1 \leq \Omega<5$.

\subsection{Natural Beach Examples}

[22] It is obviously impossible to match simultaneously the Froude, Shields, Rouse and density ratio numbers of downscaled laboratory movable bed experiments with those encountered in nature. As discussed in section 2.2, a good compromise has been found by using a lightweight sediment with a relatively large diameter.

[23] To confirm that this choice is morphologically relevant, we consider two examples of natural beaches, namely Duck (North Carolina [Lee et al., 1998]) and the Lido beach (Sète, France [Certain et al., 2005; Certain and Barusseau, 2005]). The tidal range is about $1.5 \mathrm{~m}$ at Duck and $0.2 \mathrm{~m}$ at Lido, thus both sites fall into the microtidal category. These two sites are therefore interesting for comparison with our 2-D constant mean water level laboratory experiments. At the year scale the closure depth is about $h_{0}=4.5 \mathrm{~m}$ at approximately $300 \mathrm{~m}$ from the shoreline at both sites. The lower part of the profiles is only modified by extreme storms. Since we cannot reproduce very large waves in the flume $\left(H_{s} \leq 20 \mathrm{~cm}\right)$, we focus on the morphodynamics of the upper part $(h<3.5 \mathrm{~m})$ of the profiles. At Duck beach [Birkemeier et al., 1985; Bayram et al., 2001] the sediment median diameter is ranging from $0.18 \mathrm{~mm}$ by $5 \mathrm{~m}$ depth to $0.4 \mathrm{~mm}$ at the shoreline. Grain size distribution at Sète beach follows the same tendency [Akouango, 1997]. It induces a mean sediment median diameter in the upper beach of $0.3 \mathrm{~mm}$, which yields a fall velocity of $w_{s} \simeq$ $4.5 \mathrm{~cm} \mathrm{~s}^{-1}$.

[24] Beach profiles observed at Duck, Lido, and produced in the Laboratoire des Ecoulements Géophysiques et Industriels (LEGI) flume are plotted in Figure 3. The Duck and Lido cross-shore profiles correspond to averages of cross-shore profiles surveyed along a $500 \mathrm{~m}$ stretch of the shore. It clearly appears that both sites have very close morphological length scales. The profiles were chosen so as to feature a bar and a terrace. The experiments have profiles very similar to those of the natural beaches with a length scale of $\lambda_{l} \simeq 1 / 10$. More precisely, bar cross-shore position, bar shape, water depth at the crest, depth at the trough, terrace depth, and mean slopes are very similar. In more detail, it can be seen that the Lido terrace profile (Figure 3b) is similar to the B2 experimental terrace profile (Figure 3c), whereas the Duck terrace profile (Figure 3a) is closer to the $\mathrm{C}$ experimental terrace profile (Figure $3 \mathrm{c}$ ). The profiles observed at Duck feature bars presenting longshore variability, such as crescentic bars (types C, D, E, and F of Lippmann and Holman [1990]). Therefore, the terrace profile of Duck is a consequence of the longshore averaging of the ridge and runnel rhythmic system. 

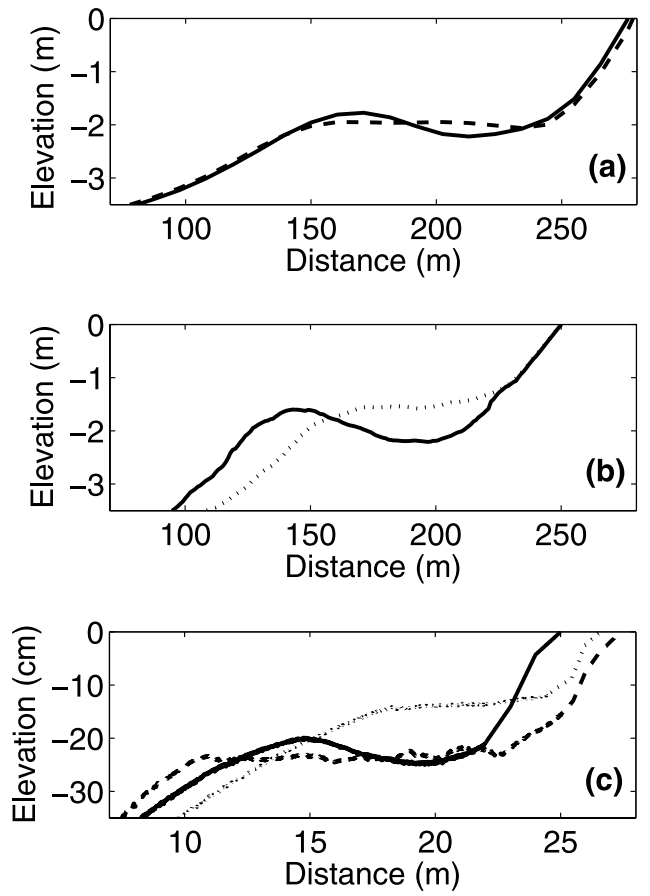

Figure 3. Measured beach profiles. (a) Duck, 4 October 1994 (solid), 7 September 1994 (dashed); (b) Lido, 25 November 2000 (solid), 1 November 2000 (dotted); and (c) LEGI wave flume, during climate B1 (solid), climate C (dashed), climate B2 (dotted). Duck and Lido cross-shore profiles are averaged over a $500 \mathrm{~m}$ long shore section. The mean water level is at 0 .

[25] As the consequence of the choice of the length scale, the timescale is $\lambda_{t} \simeq 1 / 3$. The dimensionless numbers (4)(10) for both natural sites and the wave climates that are related to the profiles of Figure 3 are given in Table 2. The numbers are computed in the shoaling region at the closure depth estimated at $4 H_{s}$ (see discussion in section 2.1). A comparison of these values with those in Table 1 clearly shows that in our experiments the Froude, Shields and Dean numbers vary in the same range, indicating that our scaling is correct, at least in the ranges of the experiments. Note that as foreseen, the wave Reynolds number is about 30 times smaller in the experiments than in nature but large enough in the breaking region $\left(\sim 10^{5}\right)$ for the flow to be turbulent. The Keulegan-Carpenter numbers in nature and in the experiments evaluated at the bar crest are $2 \times 10^{-4}$ and $3 \times 10^{-3}$, respectively, implying that the particle Reynolds numbers at both sites and in our experiments are very close. Hence both the Shields numbers and the particle Reynolds numbers of our experiments are close to those found at Duck and Lido. This places our experiments and in situ conditions at the same point in the Shields diagram. It is clear that the field wave conditions fall in the intermediate range as defined by Wright and Short [1984] since $\Omega$ is between 2.4 and 4 .

[26] On the one hand, the Duck and Lido barred profiles (Figures $3 \mathrm{a}$ and $3 \mathrm{~b}$, respectively) were observed after mild wave climates lasting 1 day. Average wave conditions for these events are $H_{s}=1.2 \mathrm{~m}$ and $T_{p}=8 \mathrm{~s}$ on 3 October (1994) at Duck beach and $H_{s}=1 \mathrm{~m}$ and $T_{p}=7 \mathrm{~s}$ on 24 November (2000) at Lido beach. On the other hand, the Duck terrace profile (Figure 3a) was preceded by 3 days of an energetic wave climate $\left(H_{s} \approx 1.75 \mathrm{~m}\right.$ and $T_{p} \approx 12 \mathrm{~s}$ that took place from 3 September until 6 September 1994). The terrace profile at Lido (Figure 3b) was measured after 6 days of weaker conditions than that of Duck $\left(H_{s} \approx 1.3 \mathrm{~m}\right.$ and $T_{p} \approx 8 \mathrm{~s}$ that took place from 20 October up to 25 October $2000)$. The aim here is not to explain in details the morphodynamics of these two beaches. It is suggested that beach profile changes could be the result of relatively energetic wave conditions over a relatively short duration. Moreover, these in situ examples show that in the intermediate range, beach profiles exhibit both terraces and bars. Following the results of a 2-year video survey at Duck beach [Lippmann and Holman, 1990], the wave climate corresponding to the most likely observed beach profile (of the attached rhythmic bar type) is characterized by $H_{s}=$ $0.9 \mathrm{~m}$ and $T_{p}=8.2 \mathrm{~s}$. The associated dimensionless numbers are given in Table 2. Considering a smaller sediment size relative to the lower beach $(0.2$ rather than $0.3 \mathrm{~mm})$ does not change much the dimensionless numbers range.

Table 2. Field Measurements and Other Laboratory Experiment Wave Conditions ${ }^{\mathrm{a}}$

\begin{tabular}{|c|c|c|c|c|c|c|c|c|c|}
\hline Site & Date & $H_{S}(\mathrm{~m})$ & $T_{p}(\mathrm{~s})$ & $d_{50}(\mathrm{~mm})$ & $\Omega$ & $\operatorname{Re}\left(\times 10^{6}\right)$ & $F r$ & $\Theta$ & Rou \\
\hline Duck & 3-6 Sep 1994 & 1.75 & 12 & 0.3 & 3.2 & 4.8 & 0.06 & 0.42 & 2.5 \\
\hline Duck & 3 Oct 1994 & 1.2 & 8 & 0.3 & 3.3 & 2.6 & 0.07 & 0.31 & 2.9 \\
\hline Duck $^{\text {b }}$ & $1986-1987$ & 0.9 & 8.2 & 0.3 & 2.4 & 1.8 & 0.06 & 0.25 & 3.3 \\
\hline Duck $^{\text {b }}$ & $1986-1987$ & 0.9 & 8.2 & 0.2 & 4 & 1.8 & 0.06 & 0.33 & 2 \\
\hline Lido & $20-25$ Oct 2000 & 1.2 & 8 & 0.3 & 3.3 & 2.6 & 0.07 & 0.31 & 2.9 \\
\hline Lido & 24 Nov 2000 & 1 & 7 & 0.3 & 3.1 & 2 & 0.07 & 0.27 & 3.1 \\
\hline Delft flume $^{c}$ & - & 0.17 & 2 & 0.1 & 10.8 & 0.12 & 0.10 & 0.15 & 1.3 \\
\hline Delft flume $^{\mathrm{d}}$ & - & 0.17 & 2.3 & 0.13 & 5.7 & 0.13 & 0.09 & 0.14 & 1.9 \\
\hline Delft flume ${ }^{\mathrm{d}}$ & - & 0.10 & 3 & 0.13 & 2.6 & 0.06 & 0.05 & 0.09 & 2.2 \\
\hline HWRL $^{\mathrm{e}}$ & - & 0.6 & 4 & 0.22 & 4.9 & 0.83 & 0.10 & 0.21 & 2.7 \\
\hline HWRL $^{\mathrm{e}}$ & - & 0.3 & 8 & 0.22 & 1.2 & 0.36 & 0.03 & 0.14 & 3.4 \\
\hline SUPERTANK $^{\mathrm{f}}$ & - & 0.8 & 4.5 & 0.22 & 5.8 & 1.26 & 0.10 & 0.26 & 2.5 \\
\hline SUPERTANK $^{\mathrm{f}}$ & - & 0.4 & 8 & 0.22 & 1.6 & 0.55 & 0.04 & 0.17 & 3.1 \\
\hline
\end{tabular}

${ }^{\text {a }}$ See related profiles of Duck and Lido beaches in Figure 3. Corresponding dimensionless numbers were computed for $h=4 H_{s}$

${ }^{\mathrm{b}}$ Field measurement analysis reported by Lippmann and Holman [1990].

${ }^{\mathrm{c}}$ Laboratory experiments reported by Roelvink and Stive [1989].

${ }^{\mathrm{d}}$ Laboratory experiments reported by Hoyng [2008].

${ }^{\mathrm{e}}$ Laboratory experiments reported by Guannel et al. [2007].

${ }^{\mathrm{f}}$ Laboratory experiments reported by Wang and Kraus [2005]. 


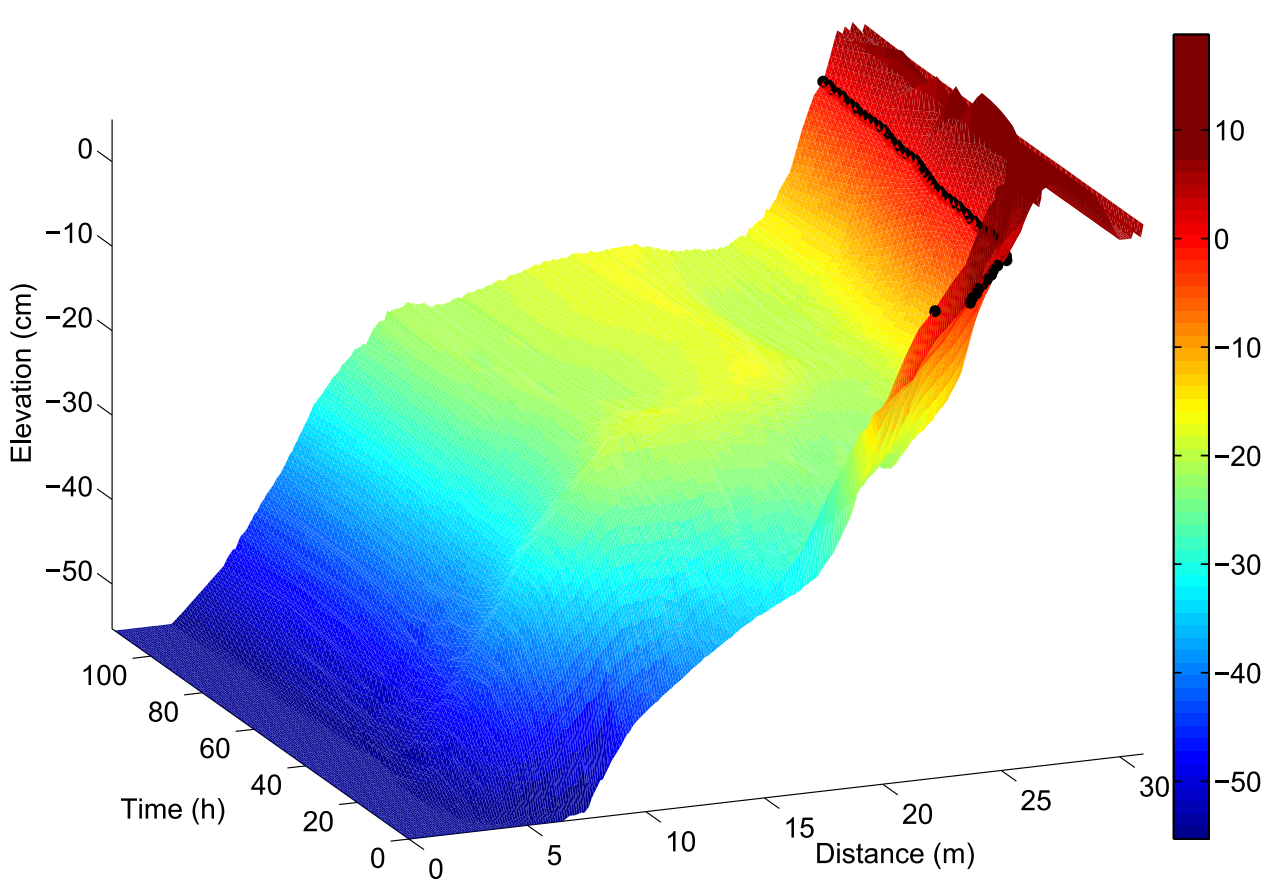

Figure 4. Beach profile changes. Terrace formation and beach face erosion for climate $\mathrm{C}(\Omega=2.5)$. The bold black symbols represent the shoreline position.

[27] Examples of wave conditions and dimensionless numbers in other laboratory experiments are also given in Table 2. These configurations use fine sand (median diameter from $0.1 \mathrm{~mm}$ to $0.22 \mathrm{~mm}$ ). The closest conditions to nature are obtained in the largest wave flume $(88 \mathrm{~m}$ long, $3.7 \mathrm{~m}$ deep [Guannel et al., 2007]). Shields numbers are generally notably smaller compared to field conditions, which probably indicates that the onset of sand transport and the transport regime are not well reproduced. This also emphasizes that it is not possible to match $\Theta$, Rou and $\Omega$ numbers simultaneously in a small-scale experiment using fine noncohesive sand.

[28] For our present experiments the dimensionless numbers $\mathrm{Fr}, \mathrm{Rou}, \Theta$ and $\Omega$ given in Table 1 are of the same order of magnitude as those of the Duck and Lido natural sites in Table 2. Note that during the shoaling process up to the breaking point, $F r$ and $\Theta$ tend to increase while Rou tends to decrease in both laboratory and natural conditions. The important point is that the choice of the lightweight sediment enables us to obtain Dean numbers in the intermediate range $0.7 \leq \Omega \leq 3.7$.

\section{Morphodynamics}

\subsection{Beach Profile Changes}

[29] Before discussing the equilibrium states, this section gives an insight into how the experimental beach morphology evolves and what type of transients are observed. Three characteristic changes are presented in Figures 4, 5, and 6.

[30] Wave climate $\mathrm{C}$ leads to beach face erosion and the formation of a so-called terrace (Figure 4). The initial profile of this experiment was a steep beach shaped by a $\Omega=3.7$ Dean number wave climate (F in Table 1$)$. In this transition to a lower Dean number $(\Omega=2.5)$, sediment is transported offshore from the upper shoreface and the overall beach slope is reduced. This kind of change can be observed in nature in the case of storm events during which the upper part of the beach is eroded and the profile switches to form a deep terrace [Günaydin and Kabdasli, 2003]. It has also been reproduced in large-scale experiments (see test A7 by Dette et al. [2002]). We note that the growth of the incident wave energy in the field generally corresponds to an increase in the value of $\Omega$. In contrast, the beach face erosion shown in Figure 4 corresponds to a decrease in $\Omega$ although the wave energy, which is proportional to $H_{s}^{2}$, has been kept constant.

[31] Wave climate E (Figure 5) corresponds to a Dean number $\Omega=3.7$ in the upper part of the intermediate range. As it evolves, the beach slope becomes steeper as sediment is transported onshore to the berm. The berm is clearly nourished. This is typical of beach profile reconstruction by fair weather waves following erosion by a strong storm [King, 1972; Sonu and James, 1973; Certain and Barusseau, 2005].

[32] In the case of climate B2 (Figure 6), the bar on the initial profile migrates onshore as a dune propagation. During migration it develops an asymmetric shape with a steeper slope shoreward. The bar sand eventually fills the trough to generate a perched terrace similar to that of case C. Onshore bar migration has been widely observed in nature, documented and discussed [e.g., Trowbridge and Young, 1989; Gallagher et al., 1998; Ruessink et al., 2007].

[33] Figure 7 presents the initial (dashed) and final (solid) beach profiles for experiments B1, B2, C, D, E, and F given in Table 1. It is worth noting that the $\Omega$ value alone does not determine whether upper shoreface of profiles are eroding or accreting. Nor does it in combination with the offshore wave steepness $H_{s} / L_{0}$, with $L_{0}$ being the offshore wavelength at the wave maker [Dette et al., 2002]. In experiments B1 and B2, the same wave forcing was imposed on 


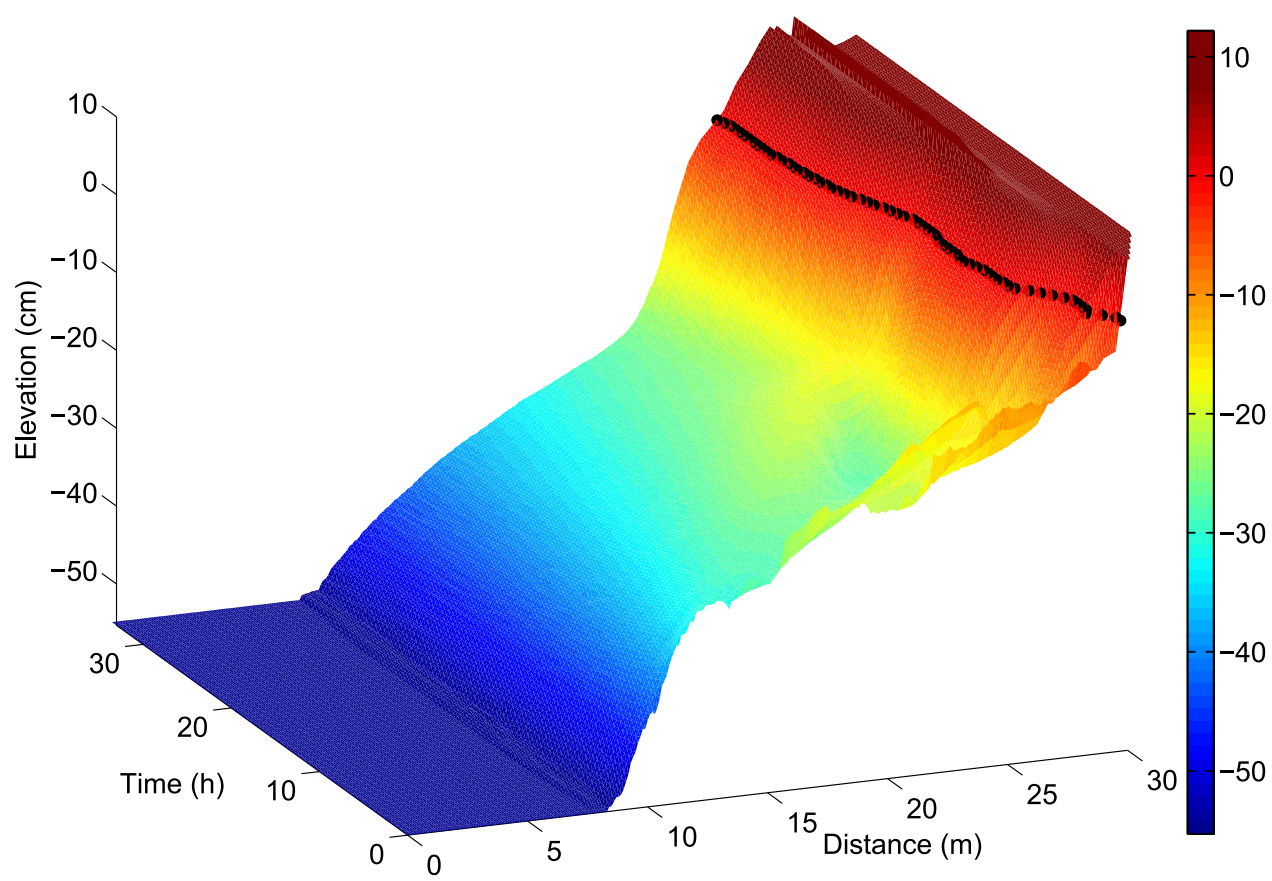

Figure 5. Beach profile changes. Bar formation, onshore migration and beach face accretion for climate $\mathrm{E}(\Omega=3.7)$. The bold black symbols represent the shoreline position.

two different initial profiles. This results in similar terrace shapes. Nonetheless, B1 produces accretion of the lower shoreface while B2 produces erosion of this part. This is due to the fact that the initial conditions in tests B1 and B2 differ strongly. However, it can be observed that B1, B2 and C $(\Omega=2.5)$ lead to beach face erosion. No back shore is noticed and the dune is close to the shoreline. This highlights the fact that steep aerial beach profiles are probably a feature of erosional profiles. In contrast, climates $\mathrm{D}, \mathrm{E}$ and $\mathrm{F}$ $(\Omega \approx 3.7)$ produce a steeper mean profile that promotes beach face accretion. This is a striking result since one would at first guess think that the higher the Dean number the milder the beach slope. However, one should recall that in the work by Wright and Short [1984] analysis this trend applies for the three states of their classification. A reflective beach has a steeper slope than an intermediate beach which

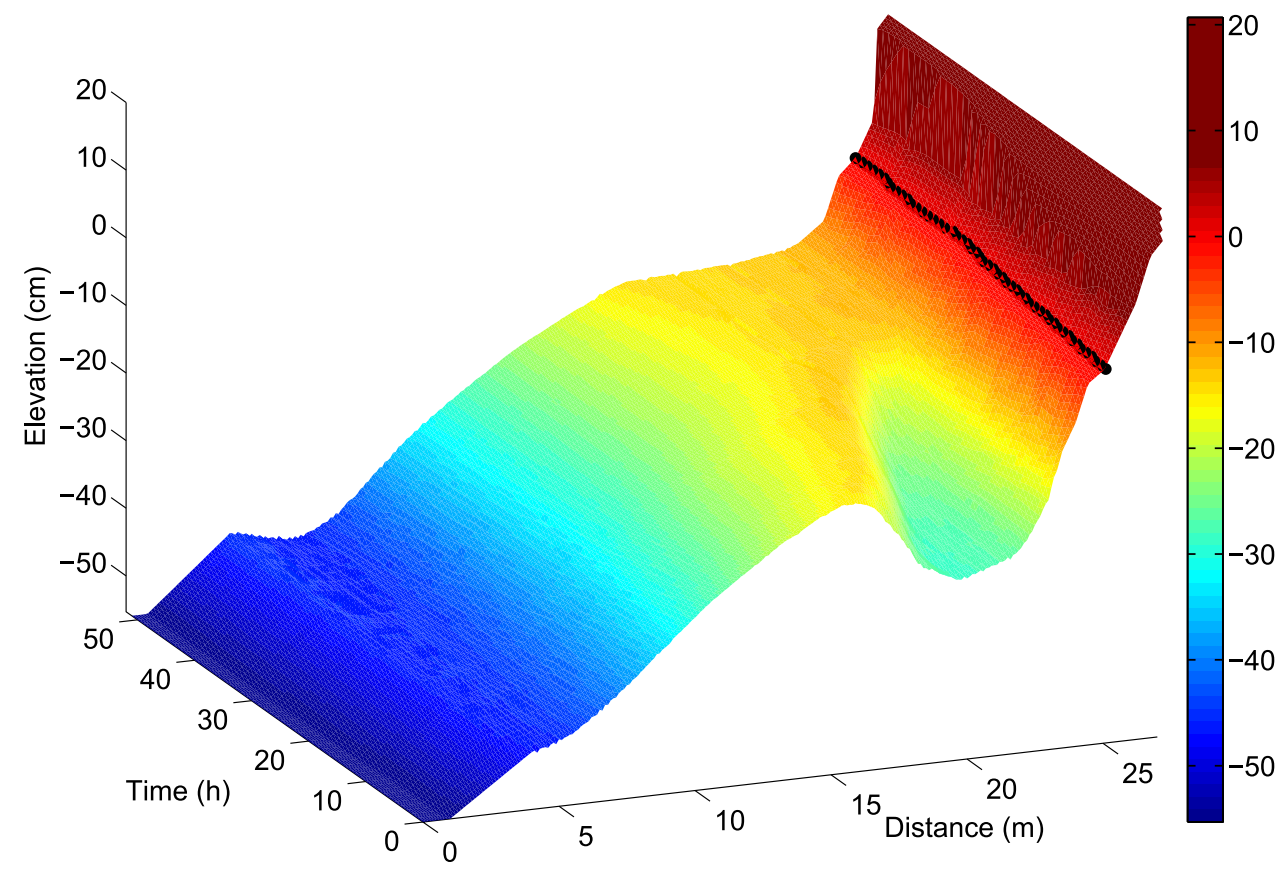

Figure 6. Beach profile changes. Onshore bar migration for climate B2 $(\Omega=2.5)$. The bold black symbols represent the shoreline position. 



Figure 7. Initial (dotted) and final (solid) beach profiles for the wave climates given in Table 1. B1, B2, and $\mathrm{C}(\Omega=2.5), \mathrm{D}(\Omega=3.6)$, and $\mathrm{E}$ and $\mathrm{F}(\Omega=3.7)$.

in turn has a steeper mean slope than a dissipative one. The Wright and Short [1984] classification does not give any refined comparison of beach slopes within the intermediate state. We also note a berm formation for $\Omega \simeq 3.7$. From a large set of field data, Ortega-Sánchez et al. [2008] concluded that a beach berm is mostly found under mean or short wave periods. For a given wave height in our experiments, a larger $\Omega$ value corresponds to a smaller wave period.

[34] The rate of change of the beach is evaluated by computing a mean velocity of bottom profile variation defined as

$$
V_{m}(t)=\frac{1}{l_{p}} \int_{x_{c}}^{x_{p}}\left|\frac{\partial h}{\partial t}\right| \mathrm{d} x,
$$

where $l_{p}$ is the profile length from the cross-shore position $x_{c}$ of the closure depth $h_{c}=4 H_{s}$ to the cross-shore position $x_{p}$ of the most offshore point on the dune that does not change during an experiment (Figure 1). The velocity of the shoreline is also computed as

$$
V_{s}(t)=\frac{\mathrm{d} x_{s}}{\mathrm{~d} t}
$$

where $x_{s}$ is the shoreline abscissa. $V_{s} \leq 0$ indicates seaward displacement, whereas $V_{s} \geq 0$ corresponds to shoreward displacement. Examples of $V_{m}$ and $V_{s}$ variations with time are shown in Figure 8 . The change at the bottom is generally rapid $\left(V_{m} \sim 10 \mathrm{~mm} \mathrm{~h}^{-1}\right)$ just after a new wave climate is initiated $(0 \leq t<2 \mathrm{~h})$. If the wave conditions are very different compared to those that have produced the initial profile, several hours may elapse before a new general shape is observed. For climate $\mathrm{C}$, for instance, $V_{m}$ remained higher than $5 \mathrm{~mm} \mathrm{~h}^{-1}$ for the first $20 \mathrm{~h}$, which corresponds to the formation of the terrace shown in Figure 4. Similarly,
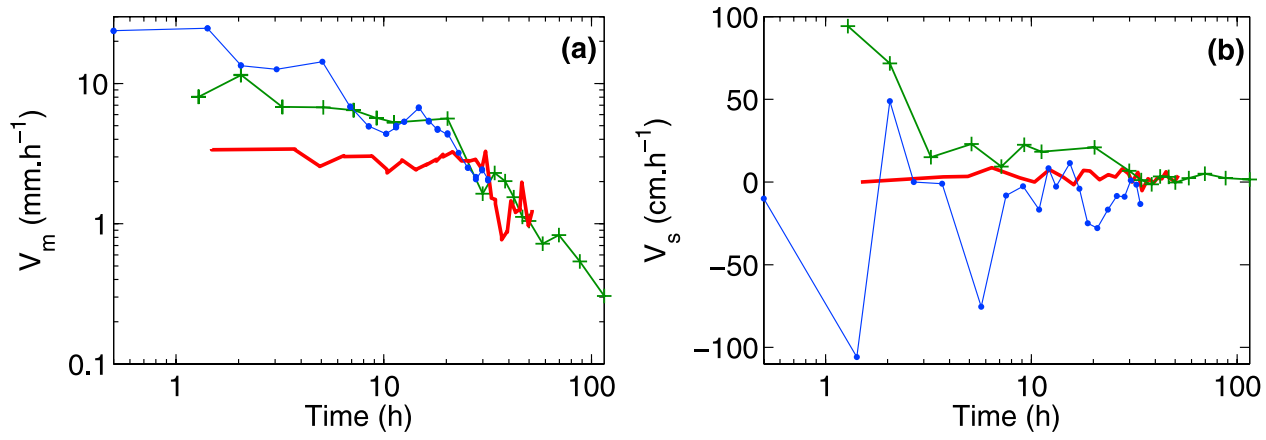

Figure 8. Bottom variation velocity for wave climates B2 (solid line), C (pluses) and E (dots). (a) Mean velocity of bottom profile variation $V_{m}$ and (b) horizontal velocity of shoreline variation $V_{s}$. 


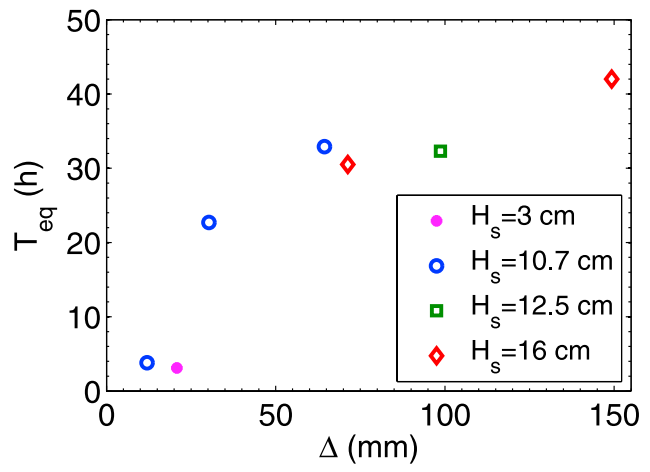

Figure 9. Time to reach equilibrium $\left(T_{e q}\right)$ as a function of the distance from initial to equilibrium bottom profiles $(\Delta)$. The seven wave climates given in Table 1 are sorted by their significant wave height $\left(H_{s}\right)$.

the shoreline velocity $V_{s}$ also drops from $100 \mathrm{~cm} \mathrm{~h}^{-1}$ to a few $\mathrm{cm} \mathrm{h}^{-1}$ in $30 \mathrm{~h}$. Once the general shape is reached, $V_{m}$ decreases to less than $2 \mathrm{~mm} \mathrm{~h}^{-1}$. This signifies slow erosion of the foreshore and an increase in the terrace length. It is worth noting that an experimental time of $30 \mathrm{~h}$ upscales to about 4 days in nature. Constant wave conditions for such a long time are rare in nature. The variation velocity $V_{m}$ never decreases to zero. The small values of $V_{m}$ observed after long experimental runs may correspond to small oscillations of the beach profile around the equilibrium state. These may be due to sediment size sorting along the profile and vertical size segregation within the bed. These slow phenomena induce small cross-shore variations in the sediment settling velocities and very long term and slow changes in the beach.

[35] The distance between the initial and the equilibrium profiles may be characterized by the averaged distance $\Delta$ defined as

$$
\Delta=\frac{1}{l_{p}} \int_{x_{c}}^{x_{p}}|\Delta h| \mathrm{d} x,
$$

where $\Delta h$ is the difference between initial and final water depth. As shown in Figure 9, the duration to reach an equilibrium state is well correlated to the distance from the initial to the final bottom profile. The trend does not depend on the wave height which implicitly enters the computation of $\Delta$ through the closure depth. The increase rate of $T_{e q}$ with $\Delta$ is not uniform and presents an asymptotic behavior. For large $\Delta$ values, increasing $\Delta$ also increases $V_{m}$ at the beginning of the experiment and consequently does not increase much $T_{e q}$.

[36] As a general conclusion, a profile is deemed to be at equilibrium when $V_{m} \approx 2 \mathrm{~mm} \mathrm{~h}^{-1}$. This criterion is applied to sort out the equilibrium states of our flume experiments. These equilibrium states are discussed with respect to the values of the dimensionless numbers.

\subsection{Equilibrium Profile Morphologies}

[37] The equilibrium beach profiles for all the wave climates listed in Table 1 are plotted in Figures 10 and 11.

[38] Wave climate forcing A with $\Omega=0.7$ (Figure 10) is weak $\left(H_{s}=3 \mathrm{~cm}\right)$ and the closure depth evaluated as $4 H_{s} \simeq$ $12 \mathrm{~cm}$ is close to the beach face. Hence only the upper beach is reshaped while the rest is a relict due to previous wave climates. A close-up of the active part is given in Figure 10. The beach face is steep with $m \sim 1 / 7$. This is typical of reflective profiles as defined by Wright and Short [1984]. This is also substantiated by computing the reflection coefficient. The surf parameter has a value of $\xi \simeq 2.1$, which yields a strong reflection coefficient of roughly $45 \%$ [Mei, 1992].

[39] We now present 2 series of experiments in the intermediate Dean number range: 1 to 5 . First of all, three wave climates with $\Omega=2.5$ (Figure 11a) associated with three beach profiles that are very similar and that display a terrace between the beach face and the lower shoreface. The terraces are at a depth $h \sim 1.1 \times H_{s}$ with mean slopes of less than $1 / 200$. These experimental runs tend to show that the lower bound of $\beta$ in (3) is the more appropriate as pointed out by Bernabeu et al. [2003]. The terraces force a large surf zone of spilling breakers. At the scale of the wavelength ( $3 \mathrm{~m}$ on the terrace) the beach faces are characterized by a steep slope ( $m \sim 1 / 10)$ with associated surf parameters $\xi$ between 0.76 and 0.94 , which indicates beach face reflections of roughly $10 \%$. The shoaling sections, which coincide with the lower shorefaces, have a slope of about $1 / 50$ that yield surf parameters between 0.15 and 0.19 . These are the lowest values obtained in our experiments. It hence appears that these profiles are a combination of a surf zone dissipative profile section and a reflective beach face.

[40] A second series of experiments with $\Omega \approx 3.7$ has been selected and plotted in Figure 11b. These profiles are characterized by a break point very close to the shoreline and located in the lower part of the beach face. These beach faces at the scale of the wavelength (roughly $3.5 \mathrm{~m}$ at the
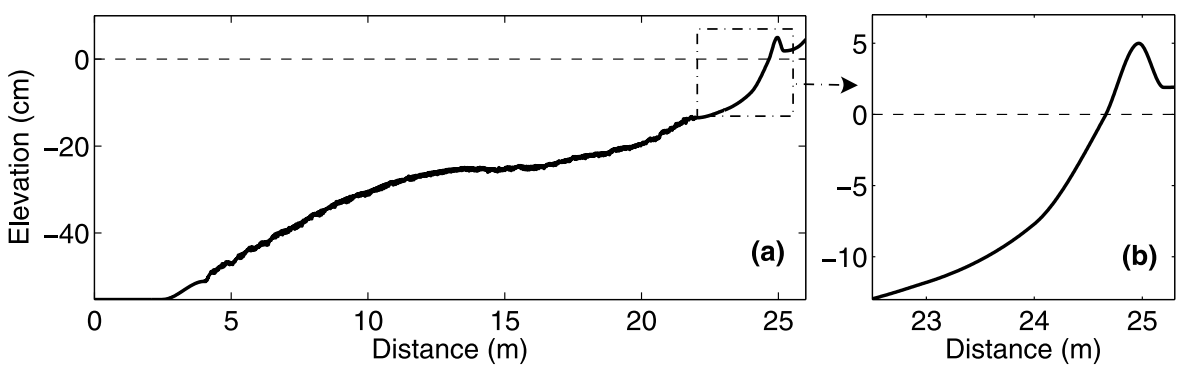

Figure 10. Equilibrium beach profile for wave climate $A(\Omega=0.7$ see Table 1). (a) Entire beach profile; and (b) close-up from the closure depth to the top of the berm. 

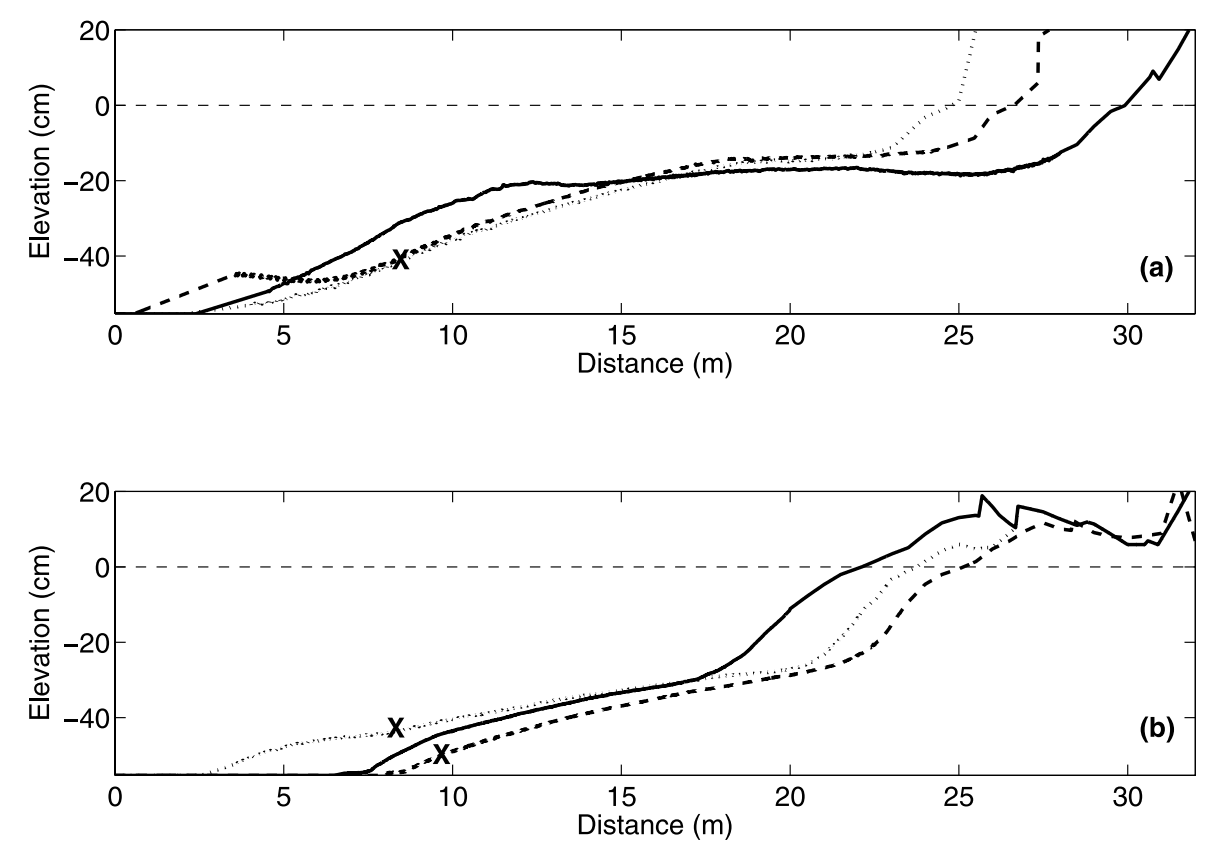

Figure 11. Equilibrium beach profiles for the wave climates given in Table 1. (a) B1 (dotted), B2 (dashed), and C (solid): $\Omega=2.5$ and (b) D (dotted), $\Omega=3.6$; and $\mathrm{E}$ (dashed) and F (solid), $\Omega=3.7$. Crosses indicate the closure depths observed during profile formation.

toe of the beach face) have slopes similar to the previous $\Omega=2.5$ cases, that is, $m \sim 1 / 10$. The surf parameter computed with these slopes ranges between 0.53 and 0.62 , which indicates very small reflection coefficients. This series of profiles also shows offshore shoaling sections $\left(2 H_{s} \leq h \leq h_{0}\right)$ that have a mild slope $(m \sim 1 / 25)$. For this slope the surf zone parameter is even smaller, at about 0.2 . Although the overall mean beach slope for the $\Omega \approx 3.7$ cases is steep, they fall in the dissipative category with regard to the surf similarity parameter.

[41] In the intermediate range explored here, the profiles show combined reflective/dissipative profiles. The associated hydrodynamic characteristics leading to these morphologies are explored in section 4.

\section{Hydrodynamics on Equilibrium Profiles}

[42] The wave-forced hydrodynamics of beaches is a very complex topic and still of interest for coastal research. Its combination with sediment transport raises this complexity a level higher. Indeed many competing sedimentary effects take place on a beach and are usually categorized into destructive and constructive forces [Dean and Dalrymple, 2001]. However, the most obvious element in this picture is the dissipation of the wave energy. Unbroken waves feed energy to the sediment phase by dissipation in the boundary layer while breaking waves will do so by both the boundary layer and the turbulence generated by breaking. Hence a first approach is to analyze how wave energy losses are distributed in the cross-shore direction. Energy loss in the surf zone is also known to generate an undertow current, which has long been recognized as a bar generation mechanism [King and Williams, 1949].

\subsection{Wave Transformation and Currents}

[43] In the shoaling zone, wave amplitude prediction can be based on the wave energy flux balance. The same energy balance equations can, with ad hoc sink terms, be used to predict wave height decay in the surf zone. These energy flux balance models can even properly predict wave modifications over nonmonotonic bottom profiles such as wave reformation [Battjes and Janssen, 1978; Thornton and Guza, 1983; Ruessink et al., 2003]. The energy balance equation reads

$$
\frac{\partial\left(E C_{g}\right)}{\partial x}=-\langle\epsilon\rangle=-\left[\left\langle\epsilon_{b}\right\rangle+\left\langle\epsilon_{f}\right\rangle\right]
$$

where $E$ is the energy density, $C_{g}$ is the group velocity, $\left\langle\epsilon_{b}\right\rangle$ is the dissipation by breaking per unit area, and $\left\langle\epsilon_{f}\right\rangle$ is the frictional dissipation. At natural sites, the frictional dissipation is negligible compared with the dominant wave breaking dissipation, except in very shallow water. Assuming that the linear theory applies both in the shoaling and surf zones, $E$ is written

$$
E=\frac{1}{8} \rho g H_{\mathrm{rms}}^{2}
$$

and $C_{g}=\sqrt{g h}$ in shallow water. Substituting (16) in (15) gives a relationship to evaluate dissipation from measured wave height decay,

$$
\langle\epsilon\rangle=-\frac{1}{8} \rho g^{3 / 2} \frac{\partial\left(H_{\mathrm{rms}}^{2} h^{1 / 2}\right)}{\partial x} .
$$



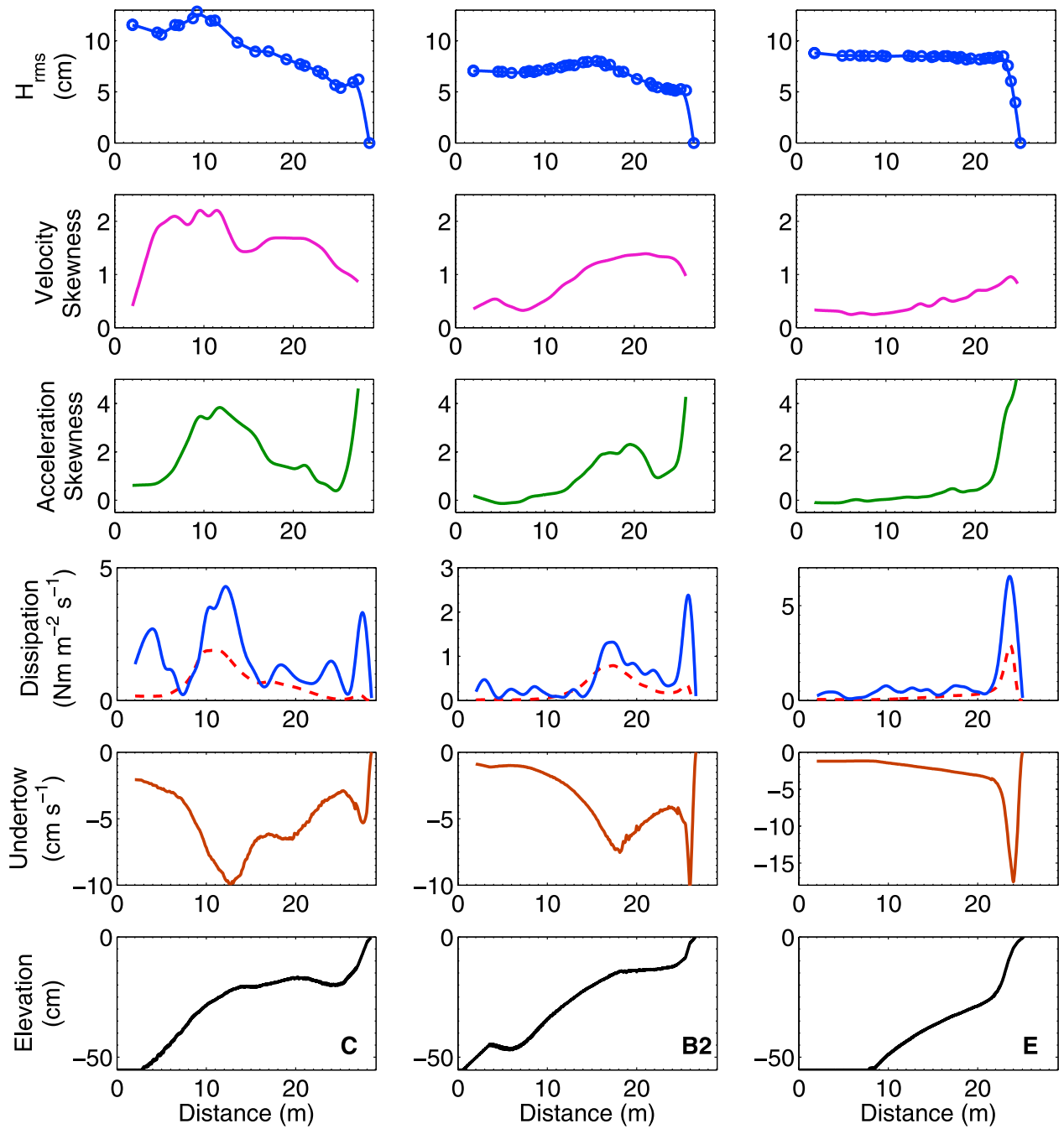

Figure 12. Hydrodynamic characterization of equilibrium states $\mathrm{C}, \mathrm{B} 2$, and $\mathrm{E}$ with, from top to bottom root-mean-square wave height, velocity skewness, acceleration skewness, measured dissipation $\langle\epsilon\rangle$ (solid) and modeled dissipation $\left\langle\epsilon_{b}\right\rangle$ (dashed), undertow, and bottom profile.

According to Thornton and Guza [1983], the bore dissipation can be evaluated as

$$
\left\langle\epsilon_{b}\right\rangle=-\frac{3 \sqrt{\pi}}{16} \rho g \frac{B^{3} H_{\mathrm{rms}}^{5}}{T_{p} \gamma^{2} h^{3}}\left[1-\frac{1}{\left(1+\left(H_{\mathrm{rms}} / \gamma h\right)^{2}\right)^{5 / 2}}\right],
$$

where $B$ and $\gamma$ are breaker coefficients 1 and 0.42 , respectively, for developed rollers. Relation (18) has been widely verified with field measurements. Relations (17) and (18) provide two independent methods to estimate wave dissipation in our experiments.

[44] The undertow current partly induced by wave breaking is estimated from the time-averaged continuity equation [Dally and Brown, 1995; Cienfuegos et al., 2009]:

$$
\frac{\mathrm{d}}{\mathrm{d} x}[U(h+\bar{\eta})]+\frac{\mathrm{d} Q_{W}}{\mathrm{~d} x}+\frac{\mathrm{d} Q_{R}}{\mathrm{~d} x}=0,
$$

where $U$ is the depth-averaged mean current, $\bar{\eta}$ is the mean water level, $Q_{W}$ is the volume flux per unit crest width associated with the organized wave motion, and $Q_{R}$ is the fluid volume flux due to the roller. In the following we use the model developed by Dally and Brown [1995] for undertow estimates. The bottom profile is often considered as the result of the balance between wave nonlinearities that transports the sediment onshore and the undertow current that distributes the sediment offshore. For long waves, the wave velocity is proportional to the free surface elevation. The crest-to-trough asymmetry or velocity skewness may be estimated as

$$
\text { Vel.Sk }=\frac{\left\langle(\eta-\bar{\eta})^{3}\right\rangle}{\left\langle(\eta-\bar{\eta})^{2}\right\rangle^{3 / 2}},
$$

where angle brackets are the time averaging operator. The front-to-lee asymmetry can be characterized by the skewness of the acceleration or the third-order moment of the 
Hilbert transform [Kennedy et al., 2000]. Here, the acceleration skewness is estimated as

$$
A c c . S k=\frac{\left\langle(\mathrm{d} \eta / \mathrm{d} t-\langle\mathrm{d} \eta / \mathrm{d} t\rangle)^{3}\right\rangle}{\left\langle(\mathrm{d} \eta / \mathrm{d} t-\langle\mathrm{d} \eta / \mathrm{d} t\rangle)^{2}\right\rangle^{3 / 2}} .
$$

\subsection{Predicted Hydrodynamics}

[45] In Figure 12 we plot some of the hydrodynamic features corresponding to equilibrium beach profiles C, B2, and $\mathrm{E}$. The root-mean-square wave height $H_{r m s}$ (top line panels) is used to compute wave energy dissipation per unit area and undertow current (lower-middle line panels). The cross-shore structure of the total dissipation $\langle\epsilon\rangle$ and of the bore dissipation $\left\langle\epsilon_{b}\right\rangle$ are comparable. The difference observed between the total dissipation (solid) and the model dissipation (dashed) can be seen as the frictional dissipation $\left\langle\epsilon_{f}\right\rangle$. This is stronger near the shoreline. The bore dissipation model parameters were calibrated by Thornton and Guza [1983] with field measurements. Note, however, the good overall agreement between $\langle\epsilon\rangle$ and $\left\langle\epsilon_{b}\right\rangle$ in the present experiments even though we chose not to recalibrate the parameters. This gives extra strength to the experimental scaling chosen.

[46] Terrace profiles $\mathrm{C}$ and $\mathrm{B} 2$, which have the same $\Omega=$ 2.5 , display similar tendencies. The waves begin to break slightly before the depth discontinuity (at $x=10 \mathrm{~m}$ for $\mathrm{C}$; $x=16 \mathrm{~m}$ for B2) and break further up beach after reforming as traveling waves on the terrace. This induces two main dissipation peaks. A lag is observed between the beginning of wave breaking and the maximum dissipation owing to the time required for the rollers to form. This is in line with previous analyses and models [Dally and Brown, 1995]. The cross-shore undertow distribution is clearly correlated to that of the dissipation. In these two cases the undertow current acts over the entire length of the step. With climate $\mathrm{C}\left(H_{s}=16 \mathrm{~cm}, T_{p}=3 \mathrm{~s}\right)$ the undertow can reach $10 \mathrm{~cm} \mathrm{~s}^{-1}$ at $x=12.5 \mathrm{~m}$, where the dissipation is maximum. This value is of the same order of magnitude as the undertow estimations by Roelvink and Stive [1989] for waves with $H_{s}=16 \mathrm{~cm}$ and $T_{p}=2 \mathrm{~s}$. In case $\mathrm{E}(\Omega=3.7)$ wave breaking is limited to the upper beach, that is, for $x \geq 23 \mathrm{~m}$. The corresponding dissipation peak induces a strong but very localized undertow (from $x=22$ to $25 \mathrm{~m}$ ) at which position the beach also shows a slope transition.

[47] It is important to note that in all cases, the dissipation peaks are located at slope transitions in the beach profiles $(x=12.5$ and $28 \mathrm{~m}$ for $\mathrm{C} ; x=17.5$ and $26 \mathrm{~m}$ for $\mathrm{B} 2 ; x=$ $24 \mathrm{~m}$ for E). Moreover the beach slope usually becomes milder as wave energy dissipation increases. It should also be emphasized that narrow beach face dissipation occurs for a basically similar steep beach face slope in all cases. Following Dean [1991], Wang and Kraus [2005] suggest that equilibrium beach profiles in the surf zone correspond to uniform volumetric wave energy dissipation. In the present experiments, relatively uniform wave energy dissipation is only observed for climate $\mathrm{C}(x \simeq 15-25 \mathrm{~m})$. Hence, the uniform surf zone dissipation does not appear to characterize all the equilibrium beach profiles. It appears to concern the beach profiles with a widely developed surf zone.

[48] The acceleration skewness (upper-middle line panels) follows a similar trend as dissipation and undertow. It reaches maximum values where dissipation is also maximum. On one hand, this occurs in the outer surf zone $(x=10$ to $15 \mathrm{~m}$ for case $\mathrm{C}$ and $x=16$ to $20 \mathrm{~m}$ for case B2). It also strongly increases in the upper beach face in all three cases. Of course this indicates that zones where the acceleration skewness is strong, the velocity as well as the surface displacement are pitched forward with "sawtooth" shapes [e.g., Elgar and Guza, 1985]. The velocity skewness does not show two maximum as the acceleration skewness does. Velocity skewness increases in the shoaling zones. It is a measure of how nonlinear the waves are. Waves that reach large values of velocity skewness have sharp crests and broad troughs. A comparison of cases $\mathrm{C}$ and B2, which have the same $\Omega=2.5$ value, clearly shows that both cases are similar in a similitude sense.

[49] The present experiments show that the cross-shore dissipation structure and the wave nonlinearities are clearly correlated to the beach profile type. Different wave climates characterized by the same Dean number induce similar hydrodynamic features.

\section{Discussion and Conclusions}

[50] This work shows that careful scaling of beach morphology is possible with lightweight sediment. In particular, the Froude, Shields and Rouse scaling is shown to be paramount. This was checked by comparing some beach profiles from our experiments with those of Duck and Lido beaches.

[51] It is shown that equilibrium profiles can be obtained in flume experiments. Beach profiles reaching equilibrium are quantified by using a bottom variation velocity. It is even conjectured that while the initial beach profile condition determines the time needed to reach equilibrium it does not strongly influence the final shape.

[52] This work also extends previous work on microtidal beach profile classification based on the Dean number. The classical classification is refined for $0.7 \leq \Omega \leq 3.7$, corresponding to the intermediate range as defined by Wright and Short [1984]. For $\Omega$ close to one, a typical reflective profile is obtained in accordance with all previous classifications. Long terraces are obtained at a depth of about $h_{r}=1.1 H_{s}$ for the $\Omega=2.5$ cases. These profiles consist of three sections, an offshore shoaling section with very little reflection, an essentially dissipative terrace and a beach face producing significant reflection. With $\Omega \approx 3.7$, the profiles are divided into 2 parts. The lower part $(h>$ $2 H_{s}$ ) has a mildly dissipative slope producing little reflection, while the beach face $\left(h<2 H_{s}\right)$ is steeper and produces slightly more reflection.

[53] The $\Omega$ value alone does not determine whether profiles are eroding or accreting. Erosion or accretion depend not only on wave conditions but also on the initial profile and how "distant" it is from the equilibrium profile. For a given wave climate, knowledge of the initial and target equilibrium profiles certainly determines how dynamic the morphological variations are. 
[54] It is shown that the cross-shore dissipation and wave nonlinearity patterns are similar for similar beach profiles, that is, with the same Dean number. The velocity skewness increases in the shoaling zone and remains large in the surf zone. The acceleration skewness is very large in the breaking zone and on the upper beach face. The dissipation peaks also coincide with bottom slope transition. More precisely, greater energy dissipation comes with milder bottom slope sections. This fits with the Wright and Short [1984] classification. While the uniformity of volumetric wave energy dissipation for equilibrium beach profiles was widely accepted, in our experiments it is not characteristic of all the equilibrium profiles. It appears to concern only a limited region of the beach profiles with a widely developed surf zone.

[55] The examination of the sediment transport along with the determination of wave nonlinearities in transient states is left aside for future work. Boussinesq-type numerical models [e.g., Cienfuegos et al., 2006, 2007] could also help for better understanding the coupling between hydrodynamics, sediment transport and morphodynamics.

[56] In our experiments, very slow profile changes are identified. This needs to be further investigated. It may be due to very slow sediment segregation along the profile but also vertically in the bed. In general barred profiles are transients in our experiments [see also Grasso et al., 2009]. What we suspect is that the bars are shaped by subsiding wave conditions after storms and under such conditions they tend to migrate to the shore and eventually merge with the berm. However, if the wave height decays very rapidly after the storm, the hydrodynamics may not be sufficient to set the sediment in motion on the bar. Beach profile changes resulting from a succession of different wave climates of defined durations is therefore an important issue.

[57] Acknowledgments. This study was funded by the LITEAU program of the French Ministry of Ecology, the INSU (LEFE-IDAO and RELIEF-MODLIT), the EC INTERREG-IIIc program under project BEACHMED-e and the ECOS-Sud program with CONYCIT (contract C07U01). The authors acknowledge the use of Duck beach data provided by the Coastal and Hydraulics Laboratory of the US Army Corps of Engineers. The technical assistance of J.-M. Barnoud is gratefully acknowledged.

\section{References}

Akouango, E. (1997), Morphodynamique et dynamique sédimentaire dans le golfe du Lion. Contribution à l'étude de la zone côtière dans l'actuelle et le quaternaire récent, Ph.D. thesis, Univ. de Perpignan, Perpignan, France.

Bailard, J. A. (1981), An energetics total load sediment transport model for a plane sloping beach, J. Geophys. Res., 86(C11), 10,938-10,954, doi:10.1029/JC086iC11p10938.

Battjes, J. A. (1974), Surf similarity, paper presented at 14th International Conference on Coastal Engineering, Coastal Eng. Res. Counc., Copenhagen, Denmark.

Battjes, J. A., and J. P. F. Janssen (1978), Energy loss and set-up due to breaking of random waves, paper presented at 16th International Conference on Coastal Engineering, Coastal Eng. Res. Counc., Hamburg, Germany.

Bayram, A., M. Larson, H. C. Miller, and N. C. Kraus (2001), Cross-shore distribution of longshore sediment transport: Comparison between predictive formulas and field measurements, Coastal Eng., 44, 79-99, doi:10.1016/S0378-3839(01)00023-0.

Bernabeu, A. M., R. Medina, and C. Vidal (2003), A morphological model of the beach profile integrating wave and tidal influence, Mar. Geol., 197, 95-116, doi:10.1016/S0025-3227(03)00087-2.

Birkemeier, W. A., H. C. Miller, S. D. Wilhem, A. E. Dewall, and C. S. Gorbics (1985), A user's guide to the Coastal Engineering Research Center's (CERC's) Field Research Facility, Instr. Rep. CERC-85-1, U.S. Army Eng. Waterways Exp. Stn., Vicksburg, Miss.
Black, K. P., R. M. Gorman, and K. R. Bryan (2002), Bars formed by horizontal diffusion of suspended sediment, Coastal Eng., 47, 53-75, doi:10.1016/S0378-3839(02)00119-9.

Bowen, A. J. (1980), The coastline of Canada, Pap. Geol. Surv. Can., 8010, $439 \mathrm{pp}$.

Certain, R., and J.-P. Barusseau (2005), Conceptual modelling of sand bars morphodynamics for a microtidal beach (Sète, France), Bull. Soc. Geol. Fr. 176(4), 343-354, doi:10.2113/176.4.343.

Certain, R., S. Meulé, V. Rey, and C. Pinazo (2005), Swell transformation on a microtidal barred-beach (Sète, France), J. Mar. Syst., 58, 19-34, doi:10.1016/j.jmarsys.2005.06.001.

Cienfuegos, R., E. Barthélemy, and P. Bonneton (2006), A fourth-order compact finite volume scheme for fully nonlinear and weakly dispersive Boussinesq-type equations. Part I: model development and analysis, Int. J. Numer. Methods Fluids, 51(11), 1217-1253, doi:10.1002/fld.1141.

Cienfuegos, R., E. Barthélemy, and P. Bonneton (2007), A fourth-order compact finite volume scheme for fully nonlinear and weakly dispersive Boussinesq-type equations. Part II: boundary conditions and validation, Int. J. Numer. Methods Fluids, 53(9), 1423-1455, doi:10.1002/fld.1359. Cienfuegos, R., E. Barthélemy, and P. Bonneton (2009), A wave-breaking model for Boussinesq-type equations including roller effects in the mass conservation equation,, J. Waterw. Port Coastal Ocean Eng., in press.

Dally, W. R. (1987), Longshore bar formation, in Coastal Sediments '87: Proceedings of a Specialty Conference on Advances in Understanding of Coastal Sediment Processes, New Orleans, Louisiana, May 12-14, 1987, edited by N. C. Kraus, pp. 71-86, Am. Soc. of Civ. Eng., New York.

Dally, W. R., and C. A. Brown (1995), A modeling investigation of the breaking wave roller with application to cross-shore currents, J. Geophys. Res., 100(C12), 24,873-24,883, doi:10.1029/95JC02868.

da Silva, P. A., A. Temperville, and F. Seabra Santos (2006), Sand transport under combined current and wave conditions: A semi-unsteady, practical model, Coastal Eng., 53, 897-913, doi:10.1016/j.coastaleng.2006. 06.010 .

Dean, R. G. (1973), Heuristic models of sand transport in the surf zone, in Engineering Dynamics of the Coastal Zone: First Australian Conference on Coastal Engineering, Sydney, May 14-17, 1973, pp. 208-214, Natl. Comm. on Coastal and Ocean Eng. of the Inst. of Eng., Sydney, Australia.

Dean, R. G. (1977), Equilibrium beach profiles: U.S. Atlantic and Gulf coasts, Ocean Eng. Rep. 12, Dep. of Civ. Eng., Univ. of Del., Newark.

Dean, R. G. (1991), Equilibrium beach profiles: Characteristics and applications, J. Coastal Res., 7(1), 53-84.

Dean, R. G., and R. A. Dalrymple (2001), Coastal Processes with Engineering Applications, Cambridge Univ. Press, Cambridge, U. K.

Dette, H., and K. Uliczka (1987), Prototype investigation on timedependent dune recession and beach erosion, in Coastal Sediments '87: Proceedings of a Specialty Conference on Advances in Understanding of Coastal Sediment Processes, New Orleans, Louisiana, May 12-14, 1987, edited by N. C. Kraus, pp. 1430-1444, Am. Soc. of Civ. Eng., New York.

Dette, H., M. Larson, J. Murphy, J. Newe, K. Peter, A. Reniers, and H. Steetzel (2002), Application of prototype flume tests for beach nourishment assessment, Coastal Eng., 47, 137-177, doi:10.1016/S0378-3839(02) 00124-2.

Dronkers, J. (2005), Dynamics of Coastal Systems, Adv. Ser. Ocean Eng., vol. 25, World Sci., Hackensack, N. J.

Elgar, S., and R. T. Guza (1985), Observations of bispectra of shoaling surface gravity waves, J. Fluid Mech., 161, 425-448, doi:10.1017/ S0022112085003007.

Elgar, S., E. L. Gallagher, and R. T. Guza (2001), Nearshore sand bar migration, J. Geophys. Res., 106(C6), 11,623-11,627, doi:10.1029/ 2000JC000389.

Foster, D. L., A. J. Bowen, R. A. Holman, and P. Natoo (2006), Field evidence of pressure gradient induced incipient motion, J. Geophys. Res., 111, C05004, doi:10.1029/2004JC002863.

Gallagher, E. L., S. Elgar, and R. T. Guza (1998), Observations of sand bar evolution on a natural beach, J. Geophys. Res., 103(C2), 3203-3215, doi:10.1029/97JC02765.

Goda, Y. (1985), Random Seas and Design of Maritime Structures, Univ. of Tokyo Press, Tokyo.

Günaydin, K., and M. S. Kabdasli (2003), Characteristics of coastal erosion geometry under regular and irregular waves, Ocean Eng., 30, 15791593, doi:10.1016/S0029-8018(03)00011-8.

Grasso, F., H. Michallet, and E. Barthélemy (2007), Infragravity waves in mobile-bed laboratory experiments, in Coastal Sediments '07: Proceedings of the Sixth International Symposium on Coastal Engineering and Science of Coastal Sediment Processes, May 13-17, 2007, New Orleans, Louisiana, pp. 235-247, Am. Soc. of Civ. Eng., Reston, Va.

Grasso, F., H. Michallet, R. Certain, and E. Barthélemy (2009), Experimental flume simulation of sandbar dynamics, J. Coastal Res., Special Issue, 56, 54-58. 
Guannel, G., H. T. Özkan-Haller, M. C. Haller, and J. T. Kirby (2007), Influence of velocity moments on sand bar movement during CROSSTEX in Coastal Sediments '07: Proceedings of the Sixth International Symposium on Coastal Engineering and Science of Coastal Sediment Processes, May 13-17, 2007, New Orleans, Louisiana, pp. 28-41, Am. Soc. of Civ. Eng., Reston, Va.

Hallermeier, R. J. (1978), Uses for a calculated limit depth to beach erosion, paper presented at 16th International Conference on Coastal Engineering, Coastal Eng. Res. Counc., Hamburg, Germany.

Henderson, S. M., J. S. Allen, and P. A. Newberger (2004), Nearshore sandbar migration predicted by an eddy-diffusive boundary layer model, J. Geophys. Res., 109, C06024, doi:10.1029/2003JC002137.

Henriquez, M., A. J. H. M. Reniers, B. G. Ruessink, M. J. F. Stive, T. P. Stanton, and D. L. Foster (2008), On the scaling of sediment transport in the nearshore, paper presented at COASTLAB 2008 Conference, Tech. Univ. of Bari, Bari, Italy.

Hoefel, F., and S. Elgar (2003), Wave-induced sediment transport and sandbar migration, Science, 299, 1885-1887, doi:10.1126/science.1081448.

Holman, H., and E. Sallenger (1993), Sand bar generation: A discussion of the Duck experiment series, J. Coastal Res., Special Issue, 15, 76-95.

Hoyng, C. (2008), Erosive and accretive coastal response, M.Sc. thesis, WL Delft Hydraul., Deltft, Netherlands.

Hsu, T.-J., S. Elgar, and R. T. Guza (2006), Wave-induced sediment transport and onshore sandbar migration, Coastal Eng., 53, 817-824, doi:10.1016/j.coastaleng.2006.04.003.

Hughes, S. A. (1995), Physical Models and Laboratory Techniques in Coastal Engineering, Adv. Ser. Ocean Eng., vol. 7, World Sci., Hackensack, N. J.

Inman, D. L., M. H. S. Elwany, and S. A. Jenkins (1993), Shore-rise and bar-berm profiles on ocean beaches, J. Geophys. Res., 98(C10), 18,18118,199, doi:10.1029/93JC00996.

Kamalinezhad, M. (2004), Plages en équilibre morphologique et hydrodynamique associée, Ph.D. thesis, Inst. Natl. Polytech. de Grenoble, Grenoble, France.

Kamalinezhad, M., H. Michallet, and E. Barthélemy (2004), Equilibre morphologique de barres de déferlement: Expériences, in Journées Nationales Génie Côtier - Génie Civil, edited by D. Levacher, P. Sergent, and A. Ouahsine, pp. 195-202, Centre Fr. du Littoral, Compiègne, France.

Kamphuis, J. W. (1985), On understanding scale effect in coastal mobile bed models, in Physical Modelling in Coastal Engineering, edited by R. A. Dalrymple, pp. 141-162, A. A. Balkema, Rotterdam.

Kennedy, A. B., Q. Chen, J. T. Kirby, and R. A. Dalrymple (2000), Boussinesq modelling of wave transformation, breaking and runup. I: 1D J. Waterw. Port Coastal Ocean Eng., 126(1), 39-48, doi:10.1061/(ASCE) 0733-950X(2000)126:1(39).

King, C. A. M. (1972), Beaches and Coasts, Edward Arnold, London.

King, C. A. M., and W. E. Williams (1949), The formation and movement of sand bars by wave action, Geogr. J., 113, 70-85.

Komar, P. D. (1998), Beach Processes and Sedimentation, Prentice-Hall, Englewood Cliffs, N. J.

Larson, M., and N. C. Kraus (1994), Temporal and spatial scales of beach profile change, Duck, North Carolina, Mar. Geol., 117, 75-94, doi:10.1016/0025-3227(94)90007-8.

Lee, G.-H., R. J. Nicholls, and W. A. Birkemeier (1998), Storm-driven variability of the beach-nearshore profile at Duck, North Carolina, USA, 1981-1991, Mar. Geol., 148(3-4), 163-177, doi:10.1016/S00253227(98)00010-3.

Lippmann, T. C., and R. A. Holman (1990), The spatial and temporal variability of sand bar morphology, J. Geophys. Res., 95(C7), 11,57511,590, doi:10.1029/JC095iC07p11575.

Masselink, G., and A. D. Short (1993), The effect of tide range on beach morphodynamics and morphology: A conceptual beach model, J. Coastal Res., 9(3), 785-800.

Mei, C. C. (1992), The Applied Dynamics of Ocean Surface Waves, Adv Ser. Ocean Eng., vol. 1, 2nd ed., World Sci., Hackensack, N. J.

Michallet, H., F. Grasso, and E. Barthélemy (2007), Long waves and beach profiles evolutions, J. Coastal Res., SI50, 221-225.
Miller, J. K., and R. G. Dean (2004), A simple new shoreline change model, Coastal Eng., 51, 531-556, doi:10.1016/j.coastaleng.2004.05.006.

Moore, B. D. (1982), Beach profile evolution in response to changes in water level and wave height, MCE thesis, Dep. of Civ. Eng., Univ. of Del., Newark.

Nielsen, P. (1992), Coastal Bottom Boundary Layers and Sediment Transport, Adv. Ser. Ocean Eng., vol. 4, World Sci., Hackensack, N. J.

Ortega-Sánchez, M., S. Fachin, F. Sancho, and M. A. Losada (2008), Relation between beachface morphology and wave climate at Trafalgar beach (Cadiz, Spain), Geomorphology, 99, 171-185, doi:10.1016/j.geomorph. 2007.10.013

Plant, N. G., B. G. Ruessink, and K. M. Wijnberg (2001), Morphologic properties derived from a simple cross-shore sediment transport model, J. Geophys. Res., 106(C1), 945-958, doi:10.1029/2000JC900143.

Ribas Prats, F. (2003), On the growth of nearshore sand bars as instability processes of equilibrium beach states, Ph.D. thesis, Univ. Politec. de Catalunya, Barcelona, Spain.

Roelvink, J. A., and M. J. F. Stive (1989), Bar-generating cross-shore flow mechanisms on a beach, J. Geophys. Res., 94(C4), 4785-4800, doi:10.1029/JC094iC04p04785.

Ruessink, B. G., and A. Kroon (1994), The behaviour of a multiple bar system in the nearshore zone of Terschelling, the Netherlands: 19651993, Mar. Geol., 121, 187-197, doi:10.1016/0025-3227(94)90030-2.

Ruessink, B. G., D. J. R. Walstraa, and H. N. Southgate (2003), Calibration and verification of a parametric wave model on barred beaches, Coastal Eng., 48, 139-149, doi:10.1016/S0378-3839(03)00023-1.

Ruessink, B. G., Y. Kuriyama, A. J. H. M. Reniers, J. A. Roelvink, and D. J. R. Walstra (2007), Modeling cross-shore sandbar behavior on the timescale of weeks, J. Geophys. Res., 112, F03010, doi:10.1029/ 2006JF000730.

Sonu, C. J., and W. R. James (1973), A Markov model for beach profile changes, J. Geophys. Res., 78(9), 1462-1471, doi:10.1029/JC078i009p01462.

Soulsby, R. L. (1997), Dynamics of Marine Sands, Thomas Telford, London.

Swart, D. H. (1974), A schematization of onshore-offshore transport, paper presented at 14th International Conference on Coastal Engineering, Coastal Eng. Res. Counc., Copenhagen, Denmark.

Thornton, E. B., and R. T. Guza (1983), Transformation of wave height distribution, J. Geophys. Res., 88(C10), 5925-5938, doi:10.1029/ JC088iC10p05925.

Thornton, E. B., R. T. Humiston, and W. Birkemeier (1996), Bar/trough generation on a natural beach, J. Geophys. Res., 101(C5), 12,097-12,110, doi:10.1029/96JC00209.

Trowbridge, J., and D. Young (1989), Sand transport by unbroken water waves under sheet flow conditions, J. Geophys. Res., 94(C8), 10,971-10,991, doi:10.1029/JC094iC08p10971.

Unal, N. E., and M. Bayazit (1998), Incipient motion of coarse particles on a slope by regular or irregular waves, J. Waterw. Port Coastal Ocean Eng., 124(1), 32-35, doi:10.1061/(ASCE)0733-950X(1998)124:1(32)

van Enckevort, I. M. J., and B. G. Ruessink (2001), Effect of hydrodynamics and bathymetry on video estimates of nearshore sandbar position, J. Geophys. Res., 106(C8), 16,969-16,979, doi:10.1029/1999JC000167.

Wang, T., and N. C. Kraus (2005), Beach profile equilibrium and patterns of wave decay and energy dissipation across the surf zone elucidated in a large-scale laboratory experiment, J. Coastal Res., 21(3), 522-534, doi: $10.2112 / 03-003.1$

Wright, L. D., and A. D. Short (1984), Morphodynamic variability of surf zones and beaches: A synthesis, Mar. Geolo., 56, 93-118, doi:10.1016/ 0025-3227(84)90008-2.

E. Barthélemy, F. Grasso, and H. Michallet, LEGI, BP53, F-38041 Grenoble CEDEX, France. (eric.barthelemy@hmg.inpg.fr; florent.grasso@ hmg.inpg.fr; herve.michallet@hmg.inpg.fr)

R. Certain, IMAGE EA4218, 52 avenue Alduy, F-66000 Perpignan, France. (certain@univ-perp.fr) 